\title{
Acroisquemia en adolescente con sospecha de COVID-19.
}

\author{
Acroischemia in adolescent with suspected Covid 19.
}

\author{
Brenda E. Giusto Laureano, Paula A. Gasser ${ }^{2}$, Carolina E. Trovina ${ }^{3}$, Carolina M. Sardi ${ }^{4}$. \\ ${ }^{1}$ Centro de Salud Toba. Secretaría de Salud Pública de la ciudad de Rosario. Rosario; Argentina. \\ ${ }^{2}$ Centro de Salud Mangrullo. Secretaría de Salud Pública de la ciudad de Rosario. Rosario; Argentina. \\ ${ }^{3}$ Centro de Salud Maradona. Secretaría de Salud Pública de la ciudad de Rosario. Rosario; Argentina. \\ ${ }^{4}$ Centro de Salud Pasteur. Secretaría de Salud Pública de la ciudad de Rosario. Rosario; Argentina.
}

\begin{abstract}
Autor por correspondencia: Carolina E. Trovina - carolinatrovina@gmail.com Conflicto de intereses: no presenta.
\end{abstract}

\section{Resumen}

Paciente de 13 años cuya madre realizo consulta telefónica al Centro de Salud Villa de Vallecas de la ciudad de Madrid, en contexto de Pandemia COVID-19, por lesión dura y violácea en primer dedo del pie izquierdo, sin dolor, de 1 semana de evolución, que en los últimos 2 días presento signos de inflamación, induración y eritema circundantes, sin aparente puerta de entrada, y sin fiebre ni sintomatología respiratoria o digestiva asociada. Se evalúo mediante fotografías y se interpreto como posible caso sospechoso de COVID-19. Se indico tratamiento con cefadroxilo oral, seguimiento telefónico y fotográfico, presentando buena evolución.

Se intenta mediante este artículo visibilizar la importancia de la detección de estas lesiones por Médicos de Familia en el primer nivel de atención y su seguimiento.

Palabras claves: Pandemia COVID-19. Sospecha de COVID-19. Acroisquemia. Lesiones en piel.

\begin{abstract}
A 13-year-old patient whose mother made a telephone consultation at the Villa de Vallecas Health Center in the city of Madrid, in the context of the COVID-19 pandemic, due to a hard and violaceous lesion on the first toe of the left foot, without pain, of 1 week of evolution, that in the last 2 days has signs of inflammation, induration and surrounding erythema, with no apparent portal of entry, and no fever or associated respiratory or digestive symptoms. It is evaluated by means of photographs and is interpreted as a possible suspected case of COVID-19. Treatment with oral cefadroxil, telephone and photographic follow-up is indicated, showing good evolution.

We try to make visible the importance of the detection of these injuries by Family Physicians at the first level of care and their follow-up.
\end{abstract}

Keywords: COVID-19 pandemic. COVID-19 suspicion. Acroischemia. Skin lesions. 


\section{Caso clínico}

Paciente varón de 13 años, sin antecedentes patológicos ni alergias a fármacos conocidos, adscripto al Centro de Salud Villa de Vallecas de la ciudad de Madrid. Su madre consulto al mismo mediante llamada telefónica, en contexto de Pandemia COVID-19, refiriendo que el adolescente presentaba lesión dura y violácea en el borde externo del primer dedo del pie izquierdo, sin dolor a la palpación y sin aparente relación con la uña, sin traumatismo previo, de 1 semana de evolución. Desde hace 2 días agrego induración y eritema circundantes, acompañado de prurito local y sin aparente puerta de entrada. Negaba tos, fiebre, mialgia y otros síntomas.

El paciente convive con sus padres y hermana pequeña, de los cuales su padre presenta tos (sin fiebre ni disnea), desde hace varias semanas, que interpretó como cuadro de atopía, por lo que se automedicó con desloratadina presentando mejoría parcial. Mientras que los demás integrantes se encuentran asintomáticos.

Además refirió que, 5 semanas antes del inicio de las lesiones, el paciente tuvo un episodio de distermia, odinofagia y tos que resolvió espontáneamente sin requerir atención médica.

Se le solicito que envíe fotos para valoración.

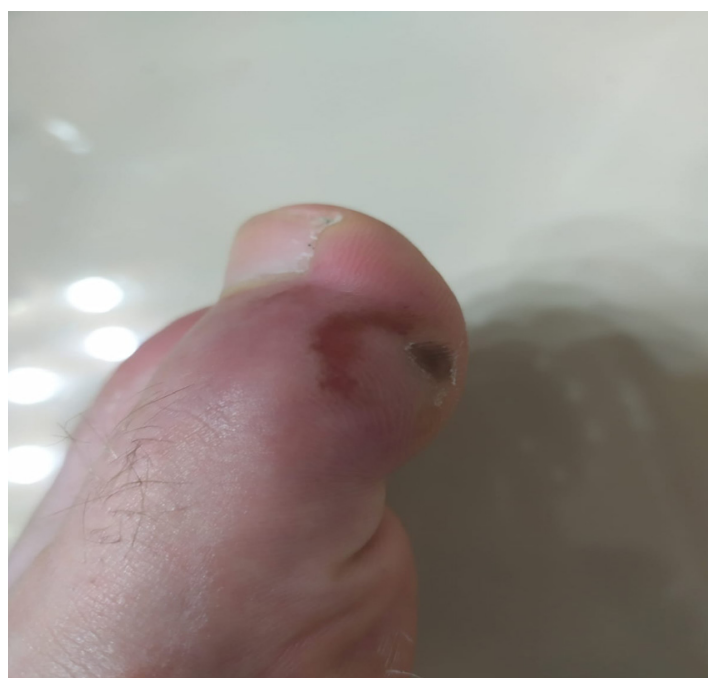

Imagen 1: Foto de la primera consulta (día 7 desde que aparece la lesión). Se observo la lesión violácea de posible origen isquémico con otra lesión semicircular eritematosa y con una induración e inflamación circundantes, sin dolor ni puerta de entrada.

Se realiza consulta vía telemática con servicio de dermatología, quienes informan que se han descripto lesiones similares en niños por COVID-19. Por lo que se interpreta al mismo como caso sospechoso de COVID-19, sin descartar la celulitis local asociada.

Se acuerda realizar tratamiento con cefadroxilo oral por 7 días, se explican signos de alarma y se pauta control telefónico cada 48 horas, con evolución favorable.

El día 12 de evolución del cuadro agrega dos nuevas lesiones, en segundo y tercer dedo del pie izquierdo, de características similares a las que presentó en consulta previa, sin signos aparentes de sobreinfección y sin otros síntomas generales. Se enviaron nuevas imágenes. 


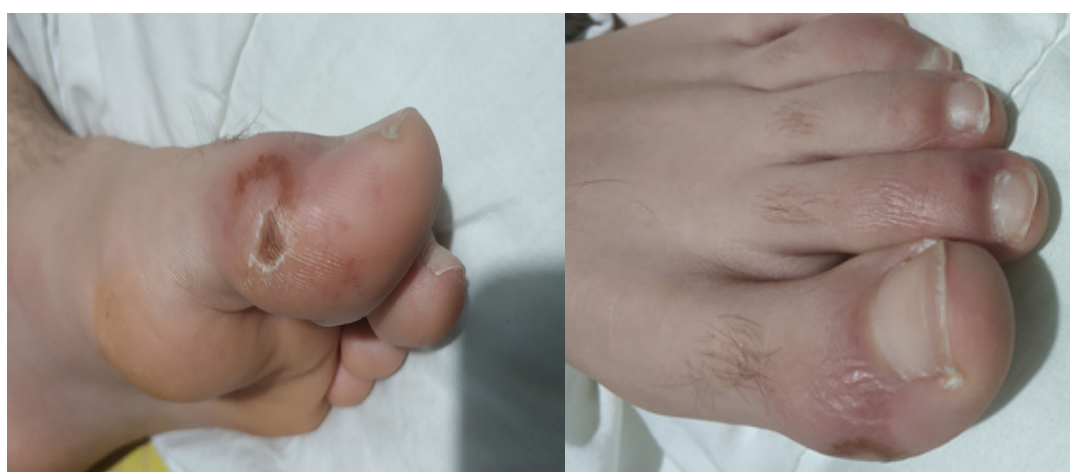

Imagen 2: Lesión tras 6 días de tratamiento antibiótico, en la que persistía la lesión principal, que ya no era violácea sino marronácea. Se constató que había disminuido considerablemente la induración y el eritema. Se objetivaron también tanto en el segundo dedo del pie ipsilateral como en el otro pie lesiones oscuras y de tinte violáceo, igualmente asintomáticas.

Se indico completar tratamiento antibiótico y se continúo con seguimiento telefónico.

El paciente finalizó tratamiento pautado, presentando buena evolución, pero con persistencia de hiperpigmentación local.

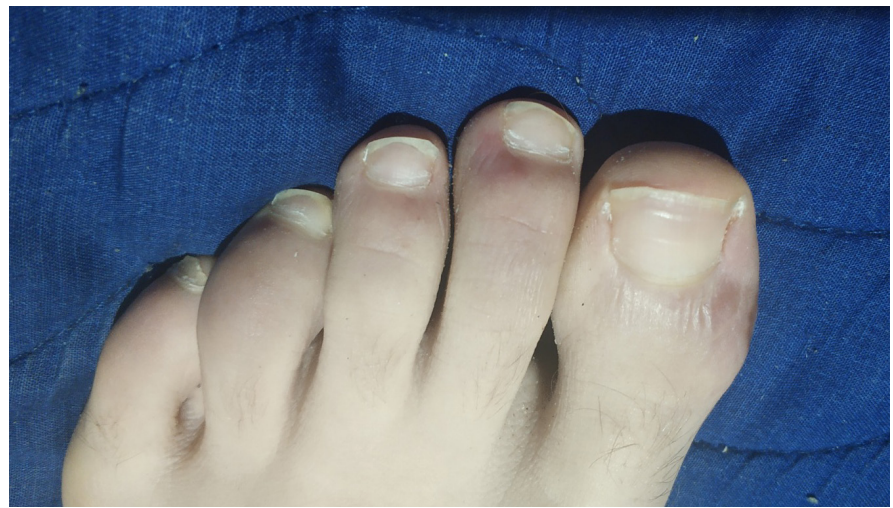

Imagen 3: Evolución de las lesiones tras 9 días desde el inicio del tratamiento antibiótico. Se objetivo la hiperpigmentación residual, sin signos de inflamación o necrosis.

\section{Discusion}

La infección por el nuevo Coronavirus (SARS-CoV-2 -Severe Acute Respiratory Syndrome Coronavirus 2-), declarado pandemia por la OMS desde el día 11 de Marzo del 2020, plantea nuevos desafíos en relación al diagnóstico según sus diferentes formas de presentación, distintas a las ya ampliamente estudiadas (sintomatología respiratoria), así como también al abordaje y seguimiento de los pacientes innovando en nuevas formas de comunicación, como lo es la telemedicina. Ésta ya empleada desde hace algún tiempo, se magnificó ante el contexto de la actual pandemia, siendo recomendada por los distintos protocolos de seguimiento de pacientes según los organismos oficiales (por ejemplo: Ministerio de Sanidad Español, Sociedad Española de Pediatría) y distintos estudios que avalan su uso (1).

En Mayo del corriente año en España se presentó un informe preliminar llamado ENE—COVID19, el cual describe un estudio longitudinal sero-epidemiológico, de base poblacional, cuyos objetivos son estimar la prevalencia de infección por SARS—Cov2 mediante la determinación de anticuerpos frente al virus y evaluar su evolución temporal. La prevalencia estimada de anticuerpos IgG frente a SARSCov2 en España es de un 5,0\%, siendo muy similar en hombres y mujeres. En relación con la edad, la prevalencia es menor en bebes, niños y en jóvenes, permaneciendo bastante estable en grupos de más edad. La prevalencia de Ig G anti Sars CoV2 según edad fue de: < 1 año: 1.1\%, 1—4 años: 2.2\%, 5 a 9 años: 3\%, 10 a 14 años 3.9\% y de 15 a 19 años: 3.8\%.

Sabiendo que la población pediátrica a cualquier edad es susceptible de ser afectada por este nuevo virus. La evidencia actual demuestra que el pronóstico en los niños suele ser mejor que en los adultos, registrándose un menor número de casos graves en relación a éstos y logrando una resolución de los 
cuadros leves de $1-2$ semanas después del inicio de la enfermedad (1)(2).

Diferentes autores han descrito lesiones similares que podrían estar en relación con la infección por SARS-CoV2, tanto de modo agudo como de modo tardío (como podría ser en el caso de nuestro paciente). La fisiopatología de estas lesiones no está clara, pero puede incluir desregulación inmune, vasculitis o, incluso, trombosis de los vasos. Dichos hallazgos descritos como lesiones acro-isquémicas (perniosis-like o pseudoperniosis) con características eritematosas, parecidas clínicamente a la perniosis («sabañones»), asintomáticas al principio, aunque después pueden provocar dolor y que aparecen en zonas acras (manos y pies). Frecuentemente observadas en pacientes jóvenes paucisintomáticos. Las lesiones pueden aparecer en cara lateral, dorso y punta de dedos, de escasos milímetros y bien delimitadas, habiéndose observado también en plantas y talones. Evolucionan durante 2 semanas tornándose purpúricas, pudiendo incluso aparecer en su evolución ampollas en la superficie de las lesiones, áreas de necrosis y hasta gangrena seca; aunque con menos frecuencia, sobre todo en pacientes graves hospitalizados (3)(4).

En el momento que fue diagnosticado el paciente no se disponía del test diagnóstico por la Reacción en Cadena de la Polimeras (PCR) en Atención Primaria en los Centros de Salud de la Comunidad de Madrid, ni test serológicos, por lo que desconocemos los datos microbiológicos o serológicos de nuestro paciente.

Fuente de financiamiento: no presenta.

\section{Referencias Bibliográficas}

1. Manejo del paciente pediátrico ante sospecha de infección por el nuevo Coronavirus Sars CoV 2 en Atención Primaria (COVID—19) AEPap-SEIP/AEP-SEPEAP 27 de abril de 2020 Estudio ENE—COVID19: Primera ronda estudio Nacional de Sero-Epidemiología de la infección por SARS—COV—2 en España Informe preliminar de Mayo de 2020. Ministerio de Sanidad de España, Consejo Interterritorial Sistema Nacional de Salud, Instituto de Salud Carlos III. Disponible: https:/www.newtral.es/wp—content/uploads/2020/05/ENE—COVID_Informe—preliminar-cierre-de-la— primera-ronda_13Mayo2020-1.pdf Recalcati, S. «Cutaneous Manifestations in COVID—19: A First Perspective». Journal of the European Academy of Dermatology and Venereology (2020); 34, $\mathrm{N}^{\circ} 5,212-213$ Mazzotta F, Troccoli T. «Monday's case. Acute acro—ischemia in the child at the timeof COVID—19». [Internet.] Dermatologia Pediatrica, Bari. Disponible en: [https://drive.google.com/file/d/lehu5OlThQLwntuDiKpfKUwitxcQF-Dh6/view]

5. Ordóñez Alonso MA, Domínguez Aurrecoechea B. Acroisquemia aguda en tiempos de COVID—19. Clínica, evolución y hallazgos de laboratorio. Rev Pediatr Aten Primaria. 2020;22: 295-303 